\title{
Service-Dominant Business Model Design for Digital Innovation in Smart Mobility
}

\author{
Oktay Turetken $\cdot$ Paul Grefen $\cdot$ Rick Gilsing $\cdot$ O. Ege Adali
}

Received: 4 March 2018/Accepted: 18 September 2018/Published online: 22 November 2018

(C) The Author(s) 2018

\begin{abstract}
In many business domains, rapid changes have occurred as a consequence of digital innovation, i.e., the application of novel information technologies to achieve specific business goals. A domain where digital innovation has great potential is smart mobility, which aims at moving around large sets of people and goods in a specific geographic setting in an efficient and effective way. So far, many innovations in this domain have concentrated on relatively isolated, technology-driven developments, such as smart route planning for individual travelers. Nice as they are, they have relatively small impact on mobility on a large scale. To achieve substantial digital innovations - for example, optimizing commuting on a city-scale - it is necessary to align the efforts and related values of a spectrum of stakeholders that need to collaborate in a common business model. To this aim, the study proposes the use of service-dominant business logic, which emphasizes the interaction of value network partners as they co-create value through collaborative
\end{abstract}

Accepted after two revisions by the editors of the special issue.

Electronic supplementary material The online version of this article (https://doi.org/10.1007/s12599-018-0565-x) contains supplementary material, which is available to authorized users.

O. Turetken $(\bowtie) \cdot$ P. Grefen · R. Gilsing · O. E. Adali

Department of Industrial Engineering and Innovation Sciences,

Eindhoven University of Technology, Den Dolech 2,

5612 AZ Eindhoven, The Netherlands

e-mail: o.turetken@tue.nl

P. Grefen

e-mail: p.w.p.j.grefen@tue.nl

R. Gilsing

e-mail: r.a.m.gilsing@tue.nl

O. E. Adali

e-mail: o.e.adali@tue.nl processes. Moving to this paradigm has significant implications on the way business is done: the business requirements for services will change faster, and the complexity of value networks required to meet these requirements will increase further. This requires new approaches to business engineering that are grounded in the premises of servicedominant logic. The paper introduces the service-dominant business model radar (SDBM/R) as an integral component of a business engineering framework. Following a design science approach, the SDBM/R has been developed in close collaboration with industry experts and evaluated through an extensive series of hands-on workshops with industry professionals from several business domains. This paper focuses on the application and evaluation in the smart mobility domain, addressing the design of new business models for digital innovation of collaborative transport of people and goods. In summary, it contributes a novel business design approach that has an academic background and relevant practical embedding.

Keywords Digital innovation - Service-dominant . Business model - Service business model $\cdot$ Business network $\cdot$ Value-in-use $\cdot$ Value co-creation $\cdot$ Smart mobility

\section{Introduction}

In many contemporary business domains, customers desire integrated solutions for their needs, instead of products that they have to deploy themselves to fulfill these needs (Vargo and Lusch 2004). In an example business-to-consumer domain, we see that customers have moved from buying traditional music playing devices (goods) to subscriptions for full-fledged music streaming services (solutions). In a business-to-business setting, we see, for 
example, that companies move away from buying transportation vehicles and instead employ integrated logistics solutions. Consequently, many organizations are transitioning into a service-dominant (SD) business setting, with the provisioning of solution-oriented services to the customers becoming the focal point (Lusch and Vargo 2006). This moves away from the traditional goods-dominant setting where the emphasis is on the delivery of products (Ostrom et al. 2010). The services may require the deployment of products, but these products become part of the delivery channel of services, not the central point. Ownership of the products becomes a less relevant issue. This transition has shifted the emphasis from the value of the individual products or services to the value of the use of the products and services in an integrated, customer-focused context, so-called value-in-use (Lusch and Vargo 2008) or value-in-context (Vargo 2009).

In the smart mobility domain, the shift to the servicedominant business is prominent. This domain is currently experiencing a strong move from an emphasis on individual vehicles and infrastructure (i.e., a goods-dominant perspective) to an emphasis on integrated services delivering a true value-in-use to end users (i.e., a servicedominant perspective). A good example in transport of people is the shift from individual ownership of cars to advanced, service-based automotive ecosystems. To illustrate this, a recent global survey of KPMG states that $85 \%$ of almost 1000 interviewed senior executives from the world's leading automotive companies agree that digital ecosystems will generate higher revenues than the hardware of cars itself (KPMG 2017). To provide complex services, there is a strong necessity for digital ecosystems to manage the flood of information associated with these services. In other words, business model innovation goes hand in hand with digital innovation (Legner et al. 2017).

In the transport of goods, we see comparable examples; instead of offering vehicles for transportation, logistics providers have started offering integrated, end-to-end logistics solutions involving multiple actors that have complex, data-driven interactions. Digital innovation is an enabler of value creation in logistics (Rai et al. 2012). In general, digital innovation is a major force for business innovation (Barrett et al. 2015), which is often driven by increasing the focus on customer experience and expectations (Abrell et al. 2016; vom Brocke 2016). This ultimately leads to a smart mobility domain providing ample opportunities for the exploitation of a service-dominant mindset with large-scale digital innovations (Böhmann et al. 2014).

The underlying digital technology in the mobility domain is referred to as C-ITS (cooperative intelligent transport systems) (Alam et al. 2016). Business-oriented layers need to be added on top of technology layers to support the viability of applying the technology in practice
(EC: C-ITS Deployment Platform 2016). In this domain, we see many small-scale digital innovations with a technologypush character. Many C-ITS applications or services, such as green light optimal speed advice (GLOSA), green priority, probe vehicle data, or roadside networks (Mitsakis et al. 2014) emerge due to increasing technological capabilities. However, these digital technologies rarely offer a value to the end user in isolation and hence have very limited impact in mobility practice. The end-user value is created by composing them into complex digital innovations which involve many building blocks, including other digital technologies. Such complex innovations, on the other hand, are hard to realize as they rely on multi-stakeholder collaboration in a real-time and data-driven context.

The delivery of these complex digital innovations requires an agile integration of the capabilities of multiple service providers and introduces the necessity of tightly managed business networks (Camarinha-Matos and Afsarmanesh 2005). Organizations no longer operate in isolation, but they collaborate in a network to deliver complex solutions (Gawer and Cusumano 2008). This requires new approaches to business model design that are grounded in the premises of service-dominant (SD) logic.

The attention for the concept of business models in academic literature is increasing (Schneider and Spieth 2013; Massa et al. 2016). Several works investigate and propose approaches for defining and representing business models (Gordijn and Akkermans 2001; Osterwalder and Pigneur 2010; Veit et al. 2014; Roelens and Poels 2015). Although many of these approaches consider cross-organizational relations and the importance of partnerships, they are typically characterized by being organizationcentric and hence reason from the perspective of a single focal company (Zolnowski et al. 2014; Turber et al. 2015).

However, given the solution-oriented nature of SD logic, a business model design approach for SD business must adopt a network-centric mindset at its core and allow for the composition of service design in multi-party business networks, which also includes the customer as a cocreator of value (Turber et al. 2014; Lusch and Nambisan 2015). Such an approach defines how actors in the business ecosystem participate in value co-creation and what the cost-benefit distribution in the network is. It operationalizes the business strategy and provides a starting point for mapping the operational processes and organizational capabilities. It also facilitates the level of business agility required to operate in service-dominant markets.

Therefore, the research objective of our work is to develop a new approach for collaborative business modeling that satisfies the aforementioned requirements of service-dominant business. Accordingly, we have developed the servicedominant business model radar (SDBM/R) as an integral part of our business engineering framework. SDBM/R is a visual 
template for representing service-dominant business models. At the centre of the template is the value-in-use, which represents the added value of a service-based solution to be realized by a network of organizations for a specific customer group. The other elements of the template include the value proposition, co-production activities, and the associated cost/benefit items for each of the involved organizations in the network. Together with its method of use, SDBM/R guides the collaborative development of service-dominant business models.

Following the design science research (DSR) methodology (Hevner et al. 2004), we developed the initial version of the SDBM/R by taking related works in the literature as a basis, but developing a new concept specifically targeted at the collaborative, agile nature of SD logic. The initial versions of the artifact were refined through a joint effort with industry experts using focus groups and workshops. Further, we evaluated the SDBM/R for its validity and utility. For evaluating validity, we organized a series of workshops, where a large number of industry professionals used the SDBM/R to collectively design new servicedominant business models in the mobility domain, in particular for solutions that address urban mobility challenges of a number of European cities. To evaluate the utility of the SDBM/R and its method of use, we performed a survey with the participants of the workshops. Our evaluation through the workshops and survey shows that SDBM/R can be considered useful for the collaborative design of service-dominant business models in the mobility domain.

The SDBM/R and its method of use aim at bridging the world of technology-push building block digital innovations (e.g., C-ITS services) and the world of requirementspull (customer-focused) digital innovations that are complex in nature. As such, the SDBM/R is a DSR-based artifact that is not a digital innovation per se, but can be used as an essential component in the generation of digital innovations in any data-driven, real-world business situation. The SDBM/R -when used effectively- leads to the generation of digital innovations that have actual impact.

The remainder of this paper is structured as follows. In Sect. 2, we provide a background on the key concepts of service-dominant business and discuss related work on the business model design. Section 3 presents the research design that we followed in constructing, applying and evaluating the SDBM/R approach. Section 4 introduces the $\mathrm{SDBM} / \mathrm{R}$ and how it can be used in practice. In Sect. 5, we present the application of the SDBM/R in the workshops that we organized with industry professionals. Here, our focus is on the smart mobility domain and the combined role of services and digital innovation. In Sect. 6, we present and discuss the results of the survey conducted with the workshop participants. Finally, Sect. 7 presents our conclusions and future research directions.

\section{Background and Related Work}

In this section, we first review the paradigm shift from goods-dominant to service-dominant business and discuss related literature on the conceptualization and design of business models. Secondly, we provide a background for the business engineering framework in which the SDBM/R approach that we introduce in this paper is integrated.

\subsection{Service-Dominant Business}

In the early $1990 \mathrm{~s}$, manufacturing companies recognized that their traditional value-chain role of producing and selling goods was becoming less profitable and that they had to move beyond the factory gate to get closer to the customer and towards providing services required to operate and maintain products (Wise and Baumgartner 1999). The product's role was increasingly seen as a mechanism for service delivery.

This shift to services is a move from the means and the producer perspective to the utilization and the customer perspective. Customers buy offerings which render services that create value (Gummesson 1995). To innovate a value is considered as a collaborative process occurring in an actor-to-actor network. It is not developed within the confines of a single organization; instead, it evolves from the joint action of a network of actors including suppliers, partners and customers - the so-called 'value network' (Chesbrough 2003; Lusch and Nambisan 2015). Co-creation of value is grounded on the fundamental idea of SD logic, which argues that humans apply their competences to benefit others and reciprocally benefit from others' applied competences through service-for-service exchange (Vargo and Lusch 2004).

Although SD logic has mainly been introduced by marketing scholars, it has a major role in driving service business design and operation, which remains largely unexplored in academic literature (Ostrom et al. 2010; Grönroos and Gummerus 2014). Transitioning to serviceoriented business requires agility not only at the level of business models, but also in the business operations and supporting IT systems. At the same time, it calls for a tight integration between the two sides of business: what services to offer and how to manage their delivery (Magretta 2002). Performing this transition and managing its consequences is a formidable task for any nontrivial business organization.

\subsection{Business Model Design and Service-Dominant Logic}

Early works provided diverse interpretations and definitions of the business model, focusing primarily on its 
conceptualization (Osterwalder and Pigneur; Timmers 1998; Amit and Zott 2001; Gordijn and Akkermans 2001; Chesbrough 2003; Shafer et al. 2005; Massa et al. 2016) and its relationships with information systems (Hedman and Kalling 2003). Later works aimed at consolidating interpretations to offer a better understanding of the concept and facilitating the process of business model design (Osterwalder and Pigneur 2010; Al-Debei and Avison 2010; Zott et al. 2011; Veit et al. 2014; Roelens and Poels 2015). AlDebei and Avison (2010) define a business model as the way in which an organization - along with its providers and partners - creates value for all its stakeholders. Taking a broader perspective, Magretta (2002) views a business model as a story that explains how an enterprise works. Well-designed business models, which ensure that business strategy, processes, and information systems harmonize, are crucial for any organization to survive and succeed (Magretta 2002; Di Valentin et al. 2012).

Business model representations have taken the form of a mixture of informal texts and graphical representations (Zott et al. 2011). Gordijn and Akkermans (2001) propose an ontology (e3-value ontology) that borrows concepts from the business literature. It uses a network-centric approach to model constellations of enterprises and end consumers who create, distribute, and consume things of economic value. An e3-value model describes the value exchanges among actors of a business network. However, it emphasizes the analysis of business models' economic feasibility through the value exchanges among actors of a business network (rather than the conceptual definition of business models and the value-in-use). The relationships between the actors in the network are mapped bilaterally, as opposed to the multilateral nature of the value network in SD business.

Following the precedent set by Gordijn and Akkermans (2001), Osterwalder and Pigneur (2002) proposed the Business Model Ontology (BMO) that formed the basis for the development of the Business Model Canvas (BMC). The BMC is a visual chart with elements describing a company's or product's value proposition, customers, infrastructure including its partnerships, and financial aspects. It has been widely adopted in practice for designing business models (Osterwalder and Pigneur 2010). However, it follows an organization-centric approach that renders the model from the perspective of a single company, as opposed to a network-centric view (Turber et al. 2015). It focuses on the processes controlled by the focal company and pays less attention to the customers' active role in value co-creation.

Adopting an organization-centric approach in business model design is a manifestation of the Goods-Dominant (GD) logic and its underlying assumption regarding the creation of value (Luftenegger et al. 2015). The organization-centric approaches adapt the value chain perspective in which the firm creates goods and pushes them out to its customers, who are then responsible for using them to fulfill only a part of their needs. Value is produced on the left side of the chain and consumed on the right hand side. The value network perspective of the SD logic, instead, supports value co-creation by a network of parties, which also includes the customer: the network as a whole creates the integrated solution that the customer needs (Lusch and Nambisan 2015). A product in the GD logic is assumed to be valuable in itself, whereas in the SD logic, it has no value unless the customer uses it (Parker et al. 2016).

With the increasing importance of services, a number of business modeling approaches have emerged that explicitly focus on services and reflect their networked view (e.g., Bouwman et al. 2008; Heikkila et al. 2008; Turber et al. 2014; Zolnowski and Böhmann 2014). The STOF framework (Bouwman et al. 2008) incorporates the service, technology, organization and finance dimensions of business models, and emphasizes the network-based creation of value. The CSOFT ontology (Heikkila et al. 2008) is built upon the same dimensions, with explicit emphasis on the customer relationship. However, these approaches do not explicitly consider the role of the customer as the co-creator of the value-in-use. These frameworks take a wider perspective in business modeling (as opposed to focusing on the essential elements) and include aspects regarding the operationalization and implementation of the solution (De Vos and Haaker 2008). Instead of a single representation for the business model, STOF incorporates a series of representations for different business model dimensions with varying degrees of detail, for instance for the technical architecture of the solution, which can pose difficulties in the ease of use and adoption of the method by practitioners with limited experience in business model design.

The works by Zolnowski et al. (2014) and Turber et al. (2014) propose representations for business models in SD business and as such offer contributions that are closer to the work presented in this paper. Zolnowski et al. (2014) introduce the Service Business Model Canvas (SBMC) which offers a representation with a stack of multiple BMCs each allotted to a specific network party, including the customer. The SBMC addresses the majority of the principles of SD logic. However, the SDBC does not explicitly take the value-in-use as a starting point for the business model. It inherits the use of the concept of valueproposition, but considers it as a value that the focal organization offers to customers and other partners through the business model. This notion does not follow the SD principles of value co-creation and reflects the GD logic rooted in the BMC. Incorporating multiple customer segments in a single representation increases the complexity of 
the representation, and makes it also difficult to reflect and communicate the process-oriented view of the service solution depicted in a business model.

Another approach that aims at the design of SD business models is the framework proposed by Turber et al. (2014, 2015). The framework specifically targets at the business models in the Internet of Things (IoT) context and features three dimensions: business network (including the customer as a co-creator of value), cost-benefit structures (for each party), and the sources of value co-creation with respect to the architectural layers of digitized objects. Although the framework has been designed to fulfill the particular requirements posed by the SD logic, the specific lens that it incorporates into its core design to cater for the IoT-driven environment makes it less capable of representing business models in other contexts. Furthermore, the framework is still in the early phases of development and requires applications in real life business settings to evaluate its effectiveness.

In brief, although the existing approaches to business model ontologies and design provide the basis for the key elements that constitute a business model, the mainstream approaches to business model design fall short of addressing the premises of the SD logic, in particular the focus on the value-in-use, the basis in a value network, the role of the customer as a co-creator in this network, and the process-oriented nature of the SDBM.

\subsection{Business Engineering Framework}

A solution-oriented service provider is concerned not only about what services to offer, but also about how to deliver them. Managing service complexity and business agility requires a close integration between the business strategy and business models on the one hand, and the structure of business operation and information technology on the other hand (Al-Debei et al. 2008). Truly agile service provisioning business is not achievable if these elements are treated in isolation.

Our previous work has introduced the essentials of a business engineering framework that puts forward the structural elements for performing service-dominant business (Grefen et al. 2013; Luftenegger 2014; Grefen and Turetken 2018). The framework (so called, BASE/X) is tuned to the essentials of SD logic (Lusch and Vargo 2008; Vargo and Lusch 2008) and is built on the existing studies on business design and engineering (Osterwalder and Pigneur; Sanz et al. 2007; Al-Debei et al. 2008; De Castro et al. 2009; Al-Debei and Avison 2010).

The framework adapts a holistic view and covers the entire spectrum from high-level business strategy definitions to business information system architecture design. It distinguishes between the business goals (the 'what' of business) and business operations (the 'how' of business) on the one hand, and between the relatively stable essence of an organization (business strategy and business services) and its agile market offerings (business models and service compositions) on the other hand. This leads to a model with four layers, as shown in Fig. 1.

The top layer, business strategy, describes the identity of an organization in a service-dominant market (Karpen et al. 2012; Luftenegger et al. 2015). The strategy is relatively stable over time: it evolves. The second layer contains service-dominant business models, describing market offering in the form of integrated solution-oriented complex services. They follow fluid market dynamics and are agile: they revolve - they are conceived, modified, and discarded as required. Business models are distinguished from the strategy as they implement part of the strategy in a more specific way. They are operationalizations of the strategy as they are more concrete.

The bottom half of the pyramid covers business operations engineering, which contains business services and service compositions. Each business service represents a core service capability of the organization. As these capabilities are related to the resources, they are relatively stable over time: they evolve. In the service compositions layer, business services are composed to realize the service functionality required by a business model: they implement a concrete value-in-use. A composition, in the form of a business process model, includes business services from the organization's own set, but also business services of partner organizations in the value network (Welke 2015). As service compositions follow business models, they are agile: they develop with their associated business models.

The framework makes an explicit distinction between the stable essence of a business organization (strategy and business services) and the agile market offerings of that organization (business models and service compositions) (Massa et al. 2016). This distinction between the stable and agile aspects is important as digital transformation requires more agility and improved responsiveness (Mingay and Mesaglio 2016). As shown in Fig. 2, engineering of the stable part of business takes place in the strategic design cycle. In this cycle, the identity and the capabilities of an

\begin{tabular}{|c|c|}
\hline $\begin{array}{l}\text { the what: } \\
\text { business } \\
\text { goal } \\
\text { engineering }\end{array}$ & $\begin{array}{r}\text { business } \\
\text { strategy } \\
\text { business } \\
\text { models }\end{array}$ \\
\hline $\begin{array}{l}\text { the how: } \\
\text { business } \\
\text { operations } \\
\text { engineering }\end{array}$ & $\begin{array}{r}\text { service } \\
\text { compositions } \\
\text { business } \\
\text { services }\end{array}$ \\
\hline
\end{tabular}

Fig. 1 Business Pyramid 
Fig. 2 Design loops and confrontation points

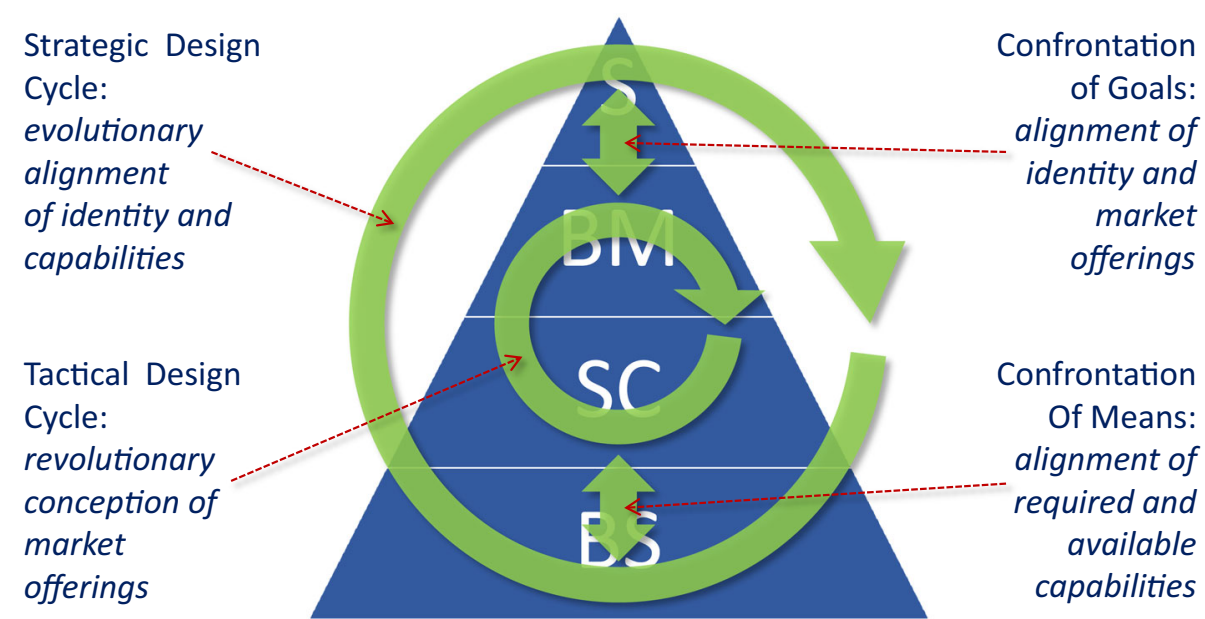

organization are aligned in an evolutionary fashion. Engineering of the agile part of business takes place in the tactic design cycle. Here, business models and their realization in service compositions are created, modified and discarded in a revolutionary fashion. The tactic design cycle 'spins' at a higher speed than the strategic design cycle. This fastpaced nature of the tactic design cycle supports managing uncertainty (in the business environment), which is essential to success in the digital era. Digitalization often needs adaptive approaches to implementing change, which can be contrasted to the traditional, predictive methods of implementing change (Mingay and Mesaglio 2016).

Alignment of both cycles takes place by confronting strategy and business models in terms of business goals, and by confronting business services and service compositions in terms of business means (as shown in Fig. 2). This alignment realizes the necessary co-engineering of stable and agile business elements.

In Luftenegger et al. (2015) we have addressed the need to translate the principles of SD logic into actionable insights for practitioners at the strategic level, where the focus is on the conceptualization, formulation, and communication of a service-dominant business strategy. This study focuses on the second layer of the framework: Business Models. Being an integral part of the framework imposes additional requirements on its design to reflect its relationship with other layers of the framework. The next section describes these requirements as a part of the overall research process that we followed in developing the SDBM/R.

\section{Research Design}

As stated in the introduction above, the objective of our research is to develop the SDBM/R - a visual template to represent service-dominant business models, which depicts the way that a network of organizations co-creates a value for a specific customer group through a solution-oriented service and generates revenue and benefits for all network parties. This paper elaborates on the design and development of the SDBM/R and its method of use, with special focus on its extensive application and evaluation in the smart mobility domain.

In developing the SDBM/R, we have followed a design science research (DSR) methodology (Hevner et al. 2004; Gregor and Hevner 2013), as our primary goal is to develop a new information systems artifact. Accordingly, our approach involved identifying the problem, defining requirements of the solution, designing and developing a satisfactory model, applying the model in a suitable context, and the evaluation of the artifact in a real life business setting to examine its validity and utility (Peffers et al. 2006; Baskerville et al. 2009).

We followed the process depicted in Fig. 3 while developing the SDBM/R. After identifying the problem through our interactions with practitioners and the review of relevant literature, we iteratively defined the requirements that our solution artifact (radar) should fulfill. Based on these requirements and insights from the review of existing literature, we developed the initial version of the SDBM/R.

Next, we performed two rounds of focus group meetings with 11 industry professionals to gather their feedback about the initial version, after which we refined the SDBM/ $\mathrm{R}$ to increase its relevancy and applicability. Following the refinement, we used the SDBM/R and followed its method of use in 3 workshops, where practitioners applied the refined version of the radar to design business models in the smart mobility domain (more specifically, traffic management). The focus groups and application of the $\mathrm{SDBM} / \mathrm{R}$ in these initial series of workshops can be considered as a light-weight (ex-ante) evaluation of the artifact to demonstrate that it works (Venable et al. 2012). The feedback gathered in these steps was helpful in refining and 


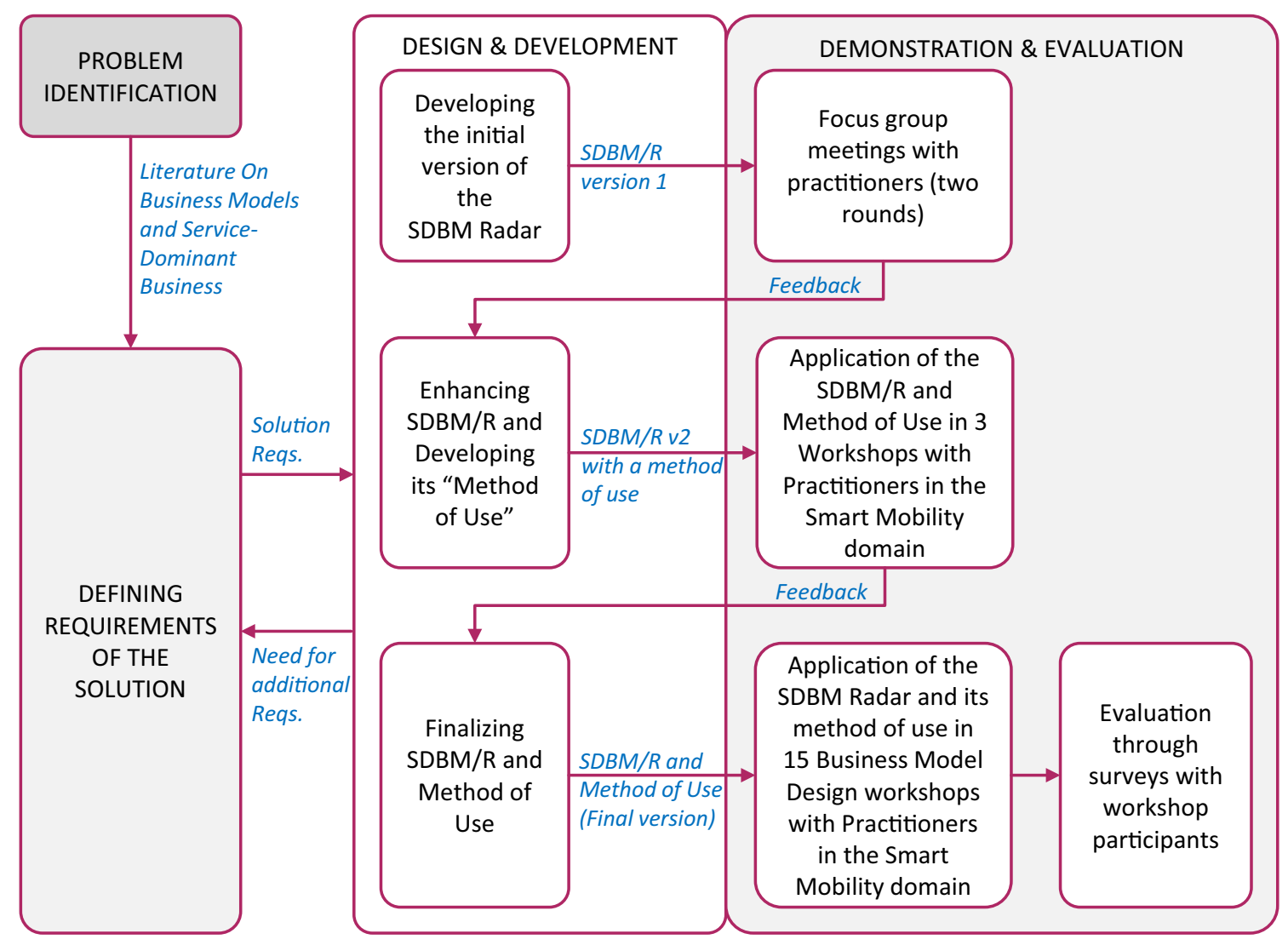

Fig. 3 Research process

finalizing the artifact (including its requirements) and ensuring its content validity.

The artifact's final version was employed in the last two steps which aimed at its application (demonstration) and ex-post evaluation (Venable et al. 2016). This involved a series of workshops where the artifact was used by practitioners in smart mobility domain to design innovative business models with an SD logic in mind. We organized 15 workshops -in total with 161 professionals- to evaluate the validity of the artifact [i.e., the extent to which it is applicable and can be used for its intended purpose of use (Gregor and Hevner 2013)]. Next, we conducted a survey with the participants of the workshops (of which 58 participants responded) to evaluate the utility of the SDBM/R, i.e., how useful and easy to use they consider the artifact to be for the design of SD business models.

The following subsections describe the details of the steps that were carried out, including the research methods applied in developing the SDBM/R. We discuss the details regarding the evaluation of SDBM/R and its method of use in Sect. 6 (after introducing the artifact and the example models which emerged from its application in Sects. 4 and 5 , respectively).

Different versions of the artifact and our intermediate experiences during their application and evaluation, as well as the resulting models that have been developed using our artifact, have been communicated with practitioners and scholars by means of a number of technical reports (Traganos et al. 2015; Grefen et al. 2016; Turetken and Grefen 2016; Turetken et al. 2018) and conference papers (Luftenegger et al. 2013; Grefen et al. 2015; Turetken and Grefen 2017). This paper sheds light on the complete research process that we went through and brings together the overall experience with additional focus and insight gained from its extensive application in the smart mobility domain.

\subsection{Problem Identification}

In the introduction section of this paper, we have provided an extensive discussion of the problem and research gap that our study aims to address. It included our recognition of the problem and research gap through several interactions with companies and our review of the existing literature on business models and SD logic.

\subsection{Defining Requirements of the Solution}

The requirements for our solution artifact are driven by the core principles of SD logic (Lusch and Vargo 2008). At the 
forefront of these principles is the emphasis on the service as a fundamental basis of exchange and consideration of products as the distribution mechanisms for services (Vargo and Lusch 2004). The focus is on the value-in-use (or value-in-context); that is, the value that the customer will obtain when the product is used in a particular context (Vargo 2009). Accordingly, the first requirement can be stated as follows:

- R1: The artifact should support taking value-in-use as a point of departure for the design of an SDBM.

The second core principle is the network centric view in business model design. Delivering complex and integrated solutions to a customer requires a network of basic business service providers (Lusch et al. 2007; Gawer and Cusumano 2008). Therefore, we state the following requirement:

- R2: The artifact should support taking a business network perspective to reflect multi-party collaboration in an SDBM.

Another aspect in the SD logic is the perspective on the role of the customer. It considers the customer as an indispensable part in the value creation process and an essential party in the co-creation of value (Lusch and Nambisan 2015). The following requirement reflects this standpoint:

- R3: The artifact should support the role of the customer as a co-creator of the value-in-use.

Each party should justify its participation in the network with a unique value offered as a part of the co-created value-in-use. A party joins the network and offers this value in exchange for benefits it expects (Lusch et al. 2007). These benefits (and costs) can take not only monetary, but also nonmonetary forms. Accordingly, we can state the following requirements:

- R4: The artifact should support the specification of the value propositions for each network party.

- R5: The artifact should support the specification of the benefits and costs in monetary and nonmonetary forms for each network party.

Unlike the case in the goods-dominant logic, a service solution in the SD logic is process oriented (Vargo and Lusch 2004). The unique value that is contributed by a party $\left(\mathrm{R}_{4}\right)$ is realized by an activity performed by that party. This activity and the effects that it creates are observable by the customer. These properties create the need to specify the activities that each network performs to realize its share of value-in-use, and to describe the way the customer experiences the creation and delivery of value-inuse (Suratno et al. 2018). The customer experience is a key input to the operationalization of business models in the form of service compositions. Accordingly, the following requirements can be stated:

- R6: The artifact should support the specification of the activities that each actor performs in the business for achieving the co-creation of value.

- R7: The artifact should support the description of the customer experience in the form of a brief account of how the customer will interact with the service solution to deliver the value-in-use.

In addition to the functional requirements listed above, we require our artifact to be considered useful and easy-touse by its users, as it is designed for being used by industry professionals, practitioners in various domains, possibly with limited experience in business model design. The artifact should make it possible to create a quick blueprint design of the business model, focusing only on the essential elements, to support communication of the idea within and outside the network and rapid and timely decision making.

These requirements collectively portray the central term in this study - i.e., the service-dominant business model (SDBM). We can define the SDBM as a representation of the way in which a network of organizations, including the providers and customer, co-creates a value for the customer through a solution-oriented service and generates revenue and benefits for all network partners.

\subsection{Developing the Initial Version of the SDBM/R}

We developed an initial version of the SDBM/R by taking as basis the requirements that we defined for our artifact in the previous step, and the existing studies on business model design and ontologies. In particular, we confronted the Business Model Canvas - BMC (Osterwalder and Pigneur 2010) with the service-dominant mindset (Luftenegger 2014). We chose BMC as a base due its strong academic foundation and high relevance for business practitioners. However, the BMC is a firm-centric model and embeds a value chain (rather than a value network) perspective for business model design. It identifies suppliers and clients at different ends of the value chain and their role in generating costs and revenues for the focal organization. This contradicts the requirements of our artifact as listed above. Accordingly, we conceptualize the service dominant business model as a collection of actors (i.e., heterogeneous entities such as businesses, firms, and customers) which interact with each other to reach shared goals, i.e., value co-creation. These entities can be viewed as socio-economic actors, connected through value propositions. They perform actions aimed at achieving desired outcomes, such as mutual value creation through co-produced solutions and experiences (Wieland et al. 
2012). Each actor has an active role in the business model through co-production activities, which eventually incur costs and benefits for everyone. We continue to elaborate on these concepts in Sect. 4, when discussing the finalized artifact.

\subsection{Focus Groups}

To increase the relevancy of the SDBM/R for practice, we organized two rounds of focus group meetings with industry experts. The selection of a focus group as a research method was mainly due to the efficiency it offers while interviewing several participants at the same time and allowing in-depth discussions in the meetings (Kontio et al. 2004). The focus group comprised 11 executives and business-unit managers of a large enterprise that offers financial services to companies operating in diverse domains. The participants had over 7 years of experience on average (the most experienced with 15 years of experience and the least with 5) in management, strategy definition, and business model design within the leasing/financial sector. The primary goal of these 1-h meetings was to capture the shortcomings of the initial version of the SDBM/R by focusing on its understandability and applicability in practice. In each meeting, the facilitator (one of the authors of this paper) presented the initial version of the SDBM/R by going through an illustrative scenario. The participants provided in-depth reviews and feedback on the elements of the SDBM/R focusing on its understandability and pragmatic use, which led to changes and simplifications in the key elements of the radar. The initial and intermediate versions of the SDBM/R are available in (Luftenegger 2014).

\subsection{Smart Mobility Business Modeling Workshops (Ex-Ante)}

The next step in the research process was to provide a setting for industry practitioners to use the improved version of the SDBM/R for designing new business models. To this aim, we selected traffic management (which is a related domain to smart mobility) as a suitable business domain to apply the SDBM/R (as discussed later in this paper in Sect. 5). We organized 3 workshops for the design of three SDBM/R blueprints and were able to bring together industry experts who represented in total 20 stakeholder firms operating in the traffic management, mobility, and interrelated domains (including event organizers, retailers, etc.). In the first part of the workshops, we presented the principles of the SD logic and introduced the $\mathrm{SDBM} / \mathrm{R}$. In the second part, the authors of this paper moderated sessions where the participants collaboratively designed SD business models around a specific business theme (e.g., traffic management in a certain district of a city during large events) using SDBM/R.

We gathered feedback from participants concerning the elements and use of the SDBM/R, as well as its potential benefits. During the workshops, we focused mainly on the method of use - i.e., the SDBM design method, but also received improvement suggestions for the elements of the radar. An example of such a suggestion involves the representation of cost-benefit flows between actors in the $\mathrm{SDBM} / \mathrm{R}$, which was incorporated in the final edition of the radar as an optional layer in the representation. The feedback gathered throughout the focus groups and workshops were helpful in finalizing the SDBM/R and its method of use and ensuring the content validity and practical relevance.

\section{SDBM Radar and Its Method of Use}

In this section, we present the final version of the SDBM/R resulting from the focus group meetings and workshops and describe how it can be effectively used for collaborative design of service-dominant business models.

\subsection{Elements of the SDBM Radar}

Figure 4 presents the elements of the SDBM/R. The cocreated value-in-use constitutes the hearth of SDBM/R (fulfilling $R_{1}$ as presented in Sect. 3.2). Following servicedominant thinking, it represents the value of a solution to a

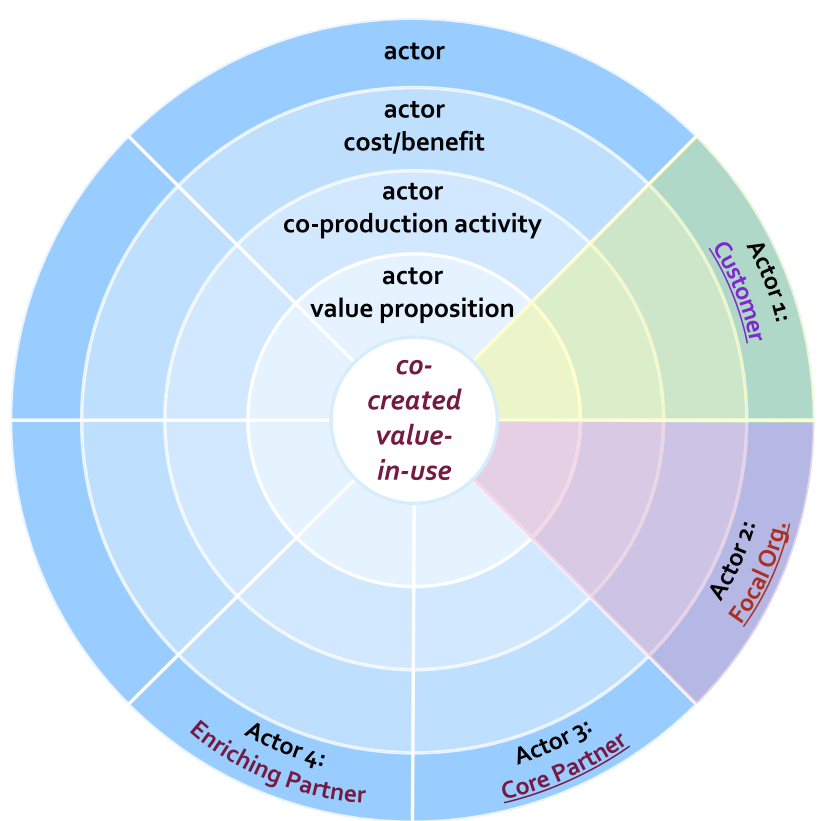

Fig. 4 Service Dominant Business Model Radar (SDBM/R) template 
customer. It is neither a service delivering the value nor a product used to produce or transfer the value.

The first concentric layer framing the value-in-use contains the actor value propositions, which represent the part of the central value-in-use contributed by a single actor $\left(R_{4}\right)$. The co-production activity defines the activities that each actor performs in the business for achieving the cocreation of value, i.e., its actor value proposition $\left(R_{6}\right)$. The effects of this activity can be observed by the customer.

The third frame, actor cost/benefits, defines the financial (monetary) and nonfinancial expenses/gains of the co-creation actors. Finally, each 'pie slice' of the radar represents a co-creation actor, including the focal organization, core and enriching partners, and the customer. We placed the labels of the actors in the fourth frame. The focal organization is often the party that initiates the setup of the business model and participates actively in the solution. The customer is always one of the parties contributing to the production of the valuein-use $\left(R_{3}\right)$. A core partner contributes actively to the essentials of the solution, while an enriching partner enhances solution's added value-in-use. SDBM/R accommodates an arbitrary number of actors, according to the network-centric character of SD business $\left(R_{2}\right)$.

All parties - including the customer - collaborate in such a way that each of them has a clear interest in the business model. Collaboration is the basis for mutual ethical benefit in terms of the SD logic. More concretely, a business model is set up to bring benefits to all parties, but also incurs costs to all parties. These benefits and costs can be of financial or nonfinancial character $\left(R_{5}\right)$. This calls for bidirectional collaboration between actors rather than an outsourcing relation, which implies a client/server relation with typically opposite interests.

A business model defines a concrete value-in-use for a concrete customer segment, and specifies its realization, i.e., the way the customer experiences the creation and delivery of this value-in-use. Therefore, a business model may take an informal scenario as a basis for inspiration, which is refined during the design process into a description of a customer experience (Bitner et al. 2008). The customer experience offers a brief description for the highlevel operation and future realization of the business model $\left(R_{7}\right)$.

\subsection{Using the SDBM Radar}

The business model design using the SDBM/R involves the following design steps:

1. Identifying and agreeing on the co-created value-in-use and the targeted customer (or customer segment). The value-in-use is the added value of a solution for the customer, who also contributes to its creation.
2. Description of the customer experience typically starts at this stage and runs in parallel with the design of the radar, often in verbal form and with several iterations, until the radar is considered complete.

3. Determining the components of the value-in-use (actor value propositions) and associated actors (roles). One actor is the focal organization, often taking the role of orchestrator. The number of actors is arbitrary, but it is recommendable to focus on the core actors at the initial stages of the design to reflect only the essence of the model. More information on the background of the concept of actors and their roles in the business model is available in (Luftenegger 2014).

4. Determining the costs and benefits for each actor. These can be of a financial or a nonfinancial character. A cost item of an actor typically relates to a benefit, often with (an)other actor(s). An optional practice at this stage is to define the cost/benefit flow among actors. (In the SDBM/R this is shown either using color codes or arrows between costs and benefits, positioned in a separate circular frame in-between the cost-benefit frame.) This flow also provides an input for the customer experience mentioned above. The sum of costs and benefits for each actor -in $a$ qualitative sense- is expected to be positive. Similarly, the business model as a whole should have a positive sum of costs and benefits from a global perspective (in qualitative terms).

5. Determining the high-level activities that realize the actor-value proposition for each actor. These activities become a part of the customer experience and can be mapped -at a later stage- to (sequences of) tasks in business processes executed by the parties in the network.

Despite the sequential design steps described above, the business model design using SDBM/R should be applied as an iterative process. The application of the radar during our workshops showed that the activities performed in step 3, i.e., determining costs and benefits, and their flow among actors have high potential to influence the decisions given in prior steps. A typical course of sequence during and after this step is to revisit the actors and their roles, as well as their value propositions as depicted in the radar, to ensure alignment between the radar and the customer experience that the actors agreed on. The outcome of this practice is a business model depicted in a radar together with the customer experience, which can be expressed textually as a story, or graphically as a story board.

A practical setup for the business model design involves a number of stakeholders brought together around a theme in a business model design session, which is moderated by a person experienced in the use of SDBM/R. The 
moderator should foster out of the box thinking while engaging the stakeholders in active communication and collaboration for innovative ideas.

\section{Using SDBM/R to Address Mobility Challenges}

In this section, we describe the particular context in which we applied/demonstrated the use of the SDBM/R. We start with a discussion of the need for SD business models in the mobility domain. Next, we present the workshops that we conducted for the design of business models to address the mobility challenges of a number of European cities. Finally, we give examples of two SDBMs that were collaboratively designed in these workshops.

\subsection{The Need for Service-Dominant Business Models in the Mobility Domain}

Increasing population and urbanization bring major challenges to cities. According to the United Nations (2014), the percentage of the world's population residing in urban areas is expected to increase from $54 \%$ (in 2014) to $66 \%$ by 2050. Given the increasing population, this is a significant rise that will intensify the existing problems and mobility challenges of urban areas.

Mobility and related domains, such as traffic management and transportation, have been confronted with a strong shift of emphasis towards the provisioning of customer-focused services to end users. These domains were traditionally characterized by their focus on product innovations and developments. The focus within innovation has been typically on developing and realizing new assets, such as roads, traffic detection systems, road signage, and cooperative intelligent transport systems (C-ITS). However, this asset-dominant orientation has two main drawbacks.

Firstly, the assets are typically very costly to develop and deploy, which means that they must be designed for strategic, long-term use. This long-term approach is, however, hard to combine with much faster changing user requirements, which are strongly related to emerging transport patterns. Organizations developing or deploying the assets observe the situation from their own, isolated perspective.

Secondly, the end users of mobility solutions are not interested in the characteristics of the individual assets, but in the added value that the use of combinations of assets provides them with (Bruns and Jacob 2014). As an example, car drivers are not so much interested in algorithms that determine traffic information on roadside signage, but in travel time reduction that can be achieved by means of traffic management.
The fact that there are multiple groups of end users (private drivers, professional drivers, institutions that need to remain accessible, the city that wants to uphold a good image) with a complex network of interactions poses further challenges when developing a business case for the deployment of these assets. When deployed effectively, C-ITS and related technology are expected to make significant contributions to a cleaner, safer and more efficient mobility (EU Parliment 2010; EC: C-ITS Deployment Platform 2016).

The abovementioned drawbacks are mainly responsible for the slow and fragmented deployment of related technologies and inhibit their potential to bring about the expected benefits (Asselin-Miller et al. 2016; EC: C-ITS Deployment Platform 2016). Research on the business model perspective of mobility and intelligent transportation systems is limited. Given that cities are often challenged to cover the intensive investments for infrastructure and service delivery, work on the business model aspects of the mobility domain has a strong practical relevance in the mobility ecosystem. There is a need for innovative business models for large-scale deployments of mobility solutions to address the urban mobility challenges and advance the value that can be reaped from the use of related technology and infrastructure (Cohen and Kietzmann 2014; Angelidou et al. 2015).

Mobility is a promising field with significant opportunities for the exploitation of service-dominant mindset (Böhmann et al. 2014). Therefore, the use of a collaborative business model design approach that explicitly focuses on value delivery to the customer and that takes into account the multi-stakeholder nature of the domain can offer significant benefits. Therefore, we address the confluence of service-dominant business and digital innovation in the design and evaluation of the SDBM/R in the smart mobility domain.

\subsection{Application of the SDBM/R in Business Model Design Workshops}

To address the urban mobility challenges faced in a number of European cities, we organized a series of business model design workshops with the participation of industry professionals working in organizations operating in the mobility and related domains. We organized 15 workshops between June 2015 and June 2018, where we asked participants to collaboratively design new business models for mobility solutions that target the particular mobility challenges faced by specific user groups. Table 1 lists these workshops, the business models that were designed, the time \& location information about the workshops, and the number of participants in each workshop. In total, we were 
Table 1 The service-dominant business model design workshops conducted in the mobility domain

\begin{tabular}{|c|c|c|c|c|}
\hline $\begin{array}{l}\text { Work- } \\
\text { shop }\end{array}$ & $\mathrm{BM}$ & Smart mobility business models (their 'value-in-use') & Location/time & $\begin{array}{l}\text { \# Participants }(161 \\
\text { in total) }\end{array}$ \\
\hline \multirow[t]{2}{*}{ Ws1 } & BM1 & Ultimate festival edition in the city & \multirow[t]{2}{*}{ Delft, NL Jun.2015 } & \multirow[t]{2}{*}{8} \\
\hline & BM2 & Most efficient container on the road & & \\
\hline \multirow[t]{2}{*}{ Ws2 } & BM3 & Free-event organization for the government & \multirow{2}{*}{$\begin{array}{l}\text { Eindhoven, NL } \\
\text { Jun.2015 }\end{array}$} & \multirow[t]{2}{*}{9} \\
\hline & BM4 & Just-in-time presence of elderly in healthcare institutions & & \\
\hline Ws3 & BM5 & Flexible on-time last mile delivery & $\begin{array}{l}\text { Rotterdam, NL } \\
\text { Jul.2015 }\end{array}$ & 7 \\
\hline Ws4 & BM6 & Fast-lane end-to-end shipping in deep-sea cargo transportation & $\begin{array}{l}\text { Rotterdam, NL } \\
\text { Jul.2015 }\end{array}$ & 5 \\
\hline \multirow[t]{2}{*}{ Ws5 } & BM7 & Convenient city visit for shopping & \multirow[t]{2}{*}{ Delft, NL Jul.2015 } & \multirow[t]{2}{*}{16} \\
\hline & BM8 & Cheap delivery intercity & & \\
\hline Ws6 & BM9 & Close-loop disintermediated intelligent delivery & $\begin{array}{l}\text { Eindhoven, NL } \\
\text { Jun.2015 }\end{array}$ & 14 \\
\hline Ws7 & BM10 & $\begin{array}{l}\text { Comfortable commuting by bike through traffic light prioritization for vulnerable } \\
\text { road users }\end{array}$ & $\begin{array}{l}\text { Helmond, NL } \\
\text { Jun. } 2017\end{array}$ & 17 \\
\hline Ws8 & BM11 & $\begin{array}{l}\text { Optimized driving experience through green light optimal speed advisory } \\
\text { (GLOSA) }\end{array}$ & $\begin{array}{l}\text { Thessaloniki, GR } \\
\text { Jul.2017 }\end{array}$ & 20 \\
\hline \multirow[t]{3}{*}{ Ws9 } & BM12 & Hassle-free concert experience with mode \& trip time advice & \multirow{3}{*}{$\begin{array}{l}\text { Copenhagen, DK } \\
\text { Aug. } 2017\end{array}$} & \multirow[t]{3}{*}{9} \\
\hline & BM13 & Reliable arrival times through mode \& trip time advice & & \\
\hline & BM14 & Safe travelling experience by warning services for vulnerable road users & & \\
\hline Ws10 & BM15 & $\begin{array}{l}\text { Green and comfortable commuting to inner city (through urban parking } \\
\text { availability and mode \& trip time advice) }\end{array}$ & $\begin{array}{l}\text { Bordeaux, FR } \\
\text { Aug. } 2017\end{array}$ & 8 \\
\hline Ws11 & BM16 & Safe driving experience with driver warning services for vulnerable road users & $\begin{array}{l}\text { Barcelona, SP } \\
\text { Sep. } 2017\end{array}$ & 20 \\
\hline \multirow[t]{2}{*}{ Ws12 } & BM17 & Efficient and effective public services via green priority & \multirow[t]{2}{*}{ Vigo, SP Sep.2017 } & \multirow[t]{2}{*}{5} \\
\hline & BM18 & $\begin{array}{l}\text { Fast and safe travel of emergency vehicles via green priority and emergency } \\
\text { vehicle warning }\end{array}$ & & \\
\hline Ws13 & BM19 & Efficient freight delivery in urban areas with parking availability & $\begin{array}{l}\text { Bilbao, SP } \\
\text { Sep.2017 }\end{array}$ & 6 \\
\hline Ws14 & BM20 & Reliable and efficient transportation via traffic information provisioning & $\begin{array}{l}\text { New Castle, UK } \\
\text { Sep. } 2017\end{array}$ & 7 \\
\hline Ws15 & BM21 & Decreased truck traffic through inner city & $\begin{array}{l}\text { Eindhoven, NL } \\
\text { June. } 2018\end{array}$ & 10 \\
\hline
\end{tabular}

able to bring together 161 practitioners collaboratively designing blueprints for 21 new business models.

Figure 5 shows further demographics of the participants, regarding their experience in the domain and the size of the companies that they work for. The majority of the participants were experienced professionals having worked in the mobility and related domains for more than 10 years (Fig. 5a), while there were variations in terms of the time they had been working in their current position (Fig. 5b).

The companies that the participants represented were of diverse size, including both SMEs and large enterprises (Fig. 5c). The companies also varied considerably in terms of type. They included private companies (such as mobility service/technology providers, telecom/mobile network operators, parking operators, etc.), and public organizations (such as municipalities, road authorities, traffic managers, public transport operators, etc.), as well as public-private partnerships or nonprofit organizations (such as automobile/motorcycle clubs, cycling associations, etc.). This helped us to elicit viewpoints of different business stakeholders in the domain.

In our survey, we also asked participants to indicate their familiarity with business model design. Figure $5 \mathrm{~d}$ shows the distribution over the set of participants, ${ }^{1}$ who also varied with respect to the knowledge/experience on business modeling. The group involved participants who considered themselves quite experienced, as well as those who had very limited knowledge on business model design.

\footnotetext{
${ }_{1}$ Please note that this question was incorporated late in our series of workshops. As a result, the graph (Fig. 5d) is based only on the responses of 20 participants.
} 
Fig. 5 Demographics of the workshop participants (a) Experience in Industry

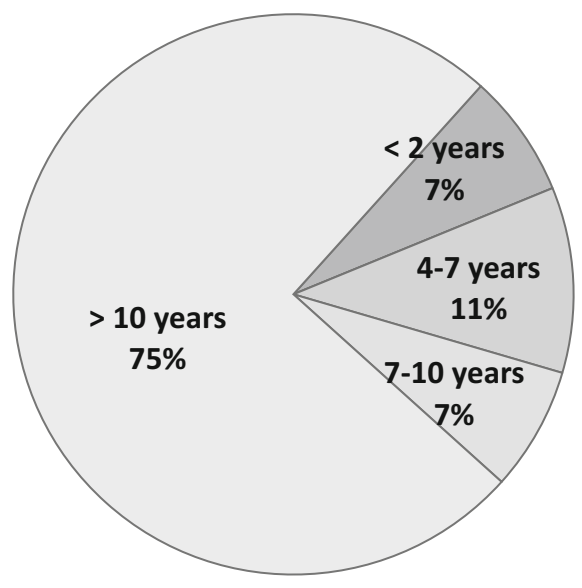

(c) Company Size

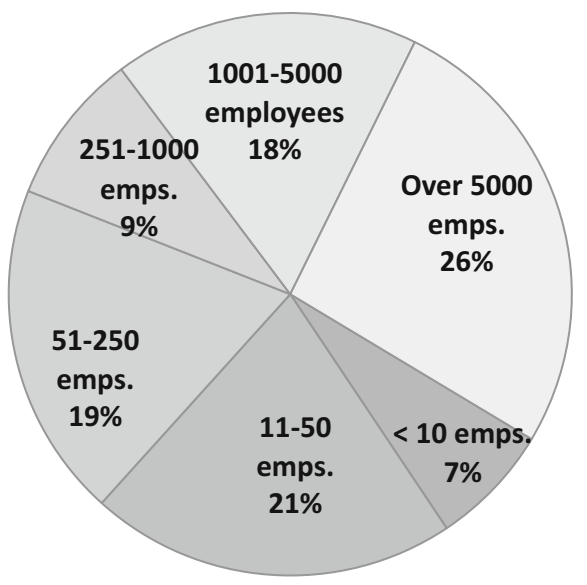

(b) Experience in current position

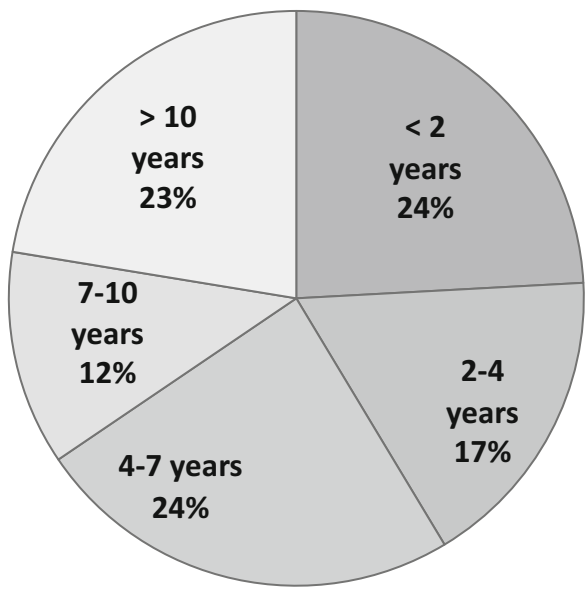

(d) Familiarity in business model design

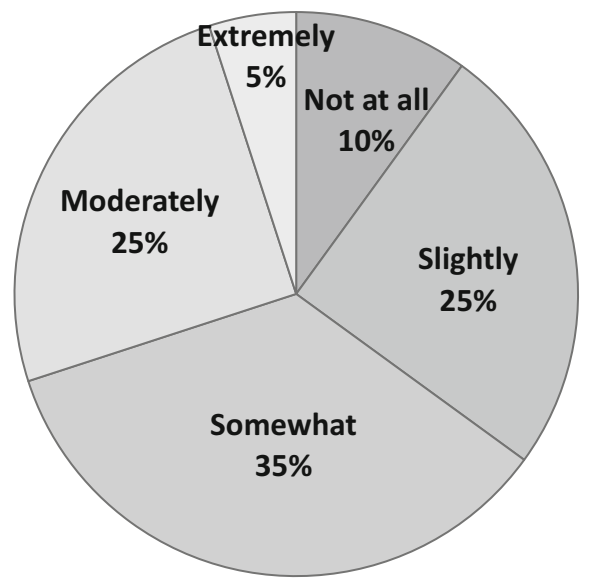

Authors of this paper participated in all workshops, and one of them acted as the moderator in each session (alternatingly). Each meeting was organized as a 2-hour workshop with two phases. The first phase involved a tutorial on the concept of service-dominant business, business engineering framework, and the use of SDBM/R. The second phase comprised the core of the collaborative design of a business model using the SDBM/R. Following a practical approach, large SDBM/R template posters and 'post-its' were used to represent the SDBM/R blueprints and its specific elements (as exemplified in the section below).

The blueprints for the business models shown in Table 1 are publicly available in a series of (technical) reports, some catalogued as related to people's mobility (Traganos et al. 2015; Grefen et al. 2016; Turetken et al. 2018) and others to the mobility of goods (Turetken and Grefen 2016). In the next subsection, we give examples of two service-dominant business models that were collaboratively designed in our workshops and target at specific urban mobility challenges of two European cities.

\subsection{Examples of Innovative Business Models in the Smart Mobility Domain}

In this section, we provide two examples of new business models in the smart mobility domain which are the basis for the practical introduction of digital innovation in traffic management. The first business model given as an example aims at addressing heavy traffic in South-East Amsterdam, particularly due to large events. The second model aims at supporting cities in their efforts to reduce car traffic in city centers. Note that, although these blueprint business models emerged from the particular context in these cities that led to the related mobility challenges, they can be used and 
concretized for other cities facing similar mobility challenges.

\subsubsection{Free-Ride Amsterdam Event}

Like most large cities, Amsterdam is characterized by heavy traffic which becomes worse during daily rush hours, but reaches its climax when large events are held in the southeast part of the city. Events, such as football matches and concerts (and all the more the combination), attract large volumes of traffic in a narrow time window. Locations to accommodate such large events are clustered in South-East Amsterdam, which consequently meets these traffic problems at regular intervals. To try and counter these problems collaboratively, we arranged a business model design workshop within the scope of a project with the participation of a large variety of stakeholders, both of the public, the private and the individual kind. The public participants included the city of Amsterdam, the province of North-Holland and the Dutch road authority. The private participants included representatives of several event location owners in the southeast section of the city, organizers of events at these locations, local retailers, parking providers, and transport providers. The third group was formed by individual road users, both car drivers and other users affected by car traffic.

Figure $6 \mathrm{~b}$ depicts the completed SDBM/R blueprint for the business model.
The Free-Ride Amsterdam Event value-in-use contributes to the positive experience of event visitors who plan their arrival by car. The idea behind the model is to attract visitors at a much earlier time than the beginning of the event, which helps reduce the traffic just before the event. This is facilitated by offering free parking, funded by parties benefiting from the early presence of the visitors (such as retailers). A number of stakeholders in the network contribute to this service. The Mobility Broker acts as the focal organization orchestrating the parties. The Parking Provider provides parking services for an easy car disposal, while the Road Authority provides the road infrastructure and traffic management before and after the event for a reliable and safe trip. Retailers are also involved by contributing to customer's experience with pre- and post-event convenience (shopping, eating, etc.).

\subsubsection{Green and Comfortable Commuting to Inner City Bordeaux}

Heavy traffic is a problem also in Bordeaux, particularly in the old city-centre which has reached its peak capacity of transport infrastructure and resources, while it is still being challenged with increasing car traffic to and from its commuter belt and demand for more parking space. The municipality has initiated programs to improve city traffic through measures for reducing car traffic in the centre and endorsing public transportation. In our business model (a)

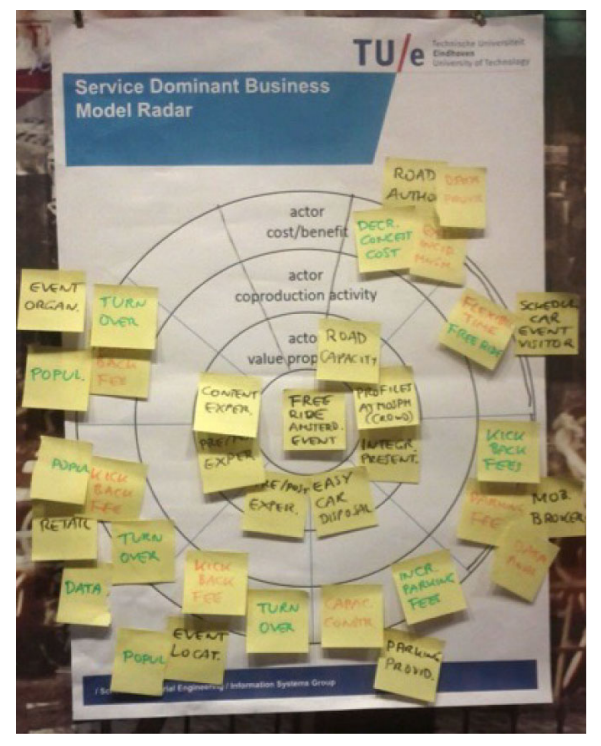

(b)

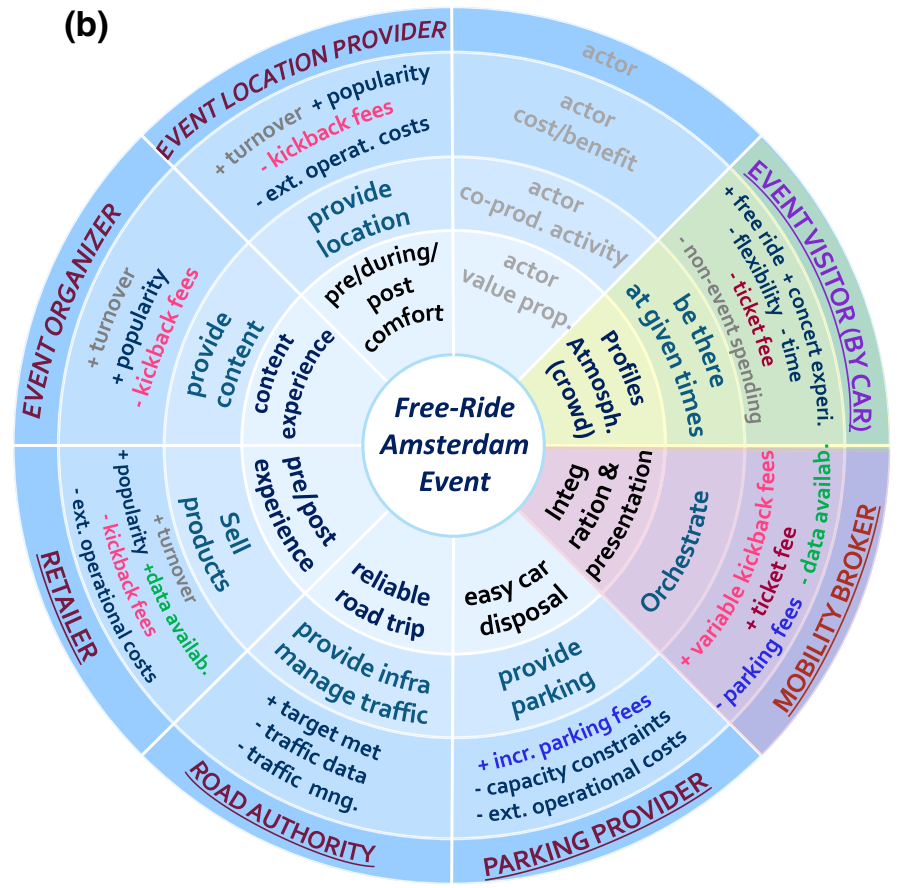

Fig. 6 The picture on the left a shows the use of the SDBM/R poster and 'post-it's during the workshop. The figure on the right b shows the business model blueprint in SDBM/R for the Free-Ride Amsterdam Event 
design workshop in Bordeaux, we targeted this challenge and designed a business model which uses the inner city commuter as customer who travels by car often on a daily basis.

Figure 7 presents the essential components of the business model blueprint that emerged from the workshop. The objective is to provide a setting with incentives for the commuters to make a model shift from driving to public transportation when approaching the dense inner city. The commuter is invited to park outside the inner city and make use of public transportation to the final travel destination.

The solution is supported by a number of C-ITS (cooperative-intelligent transportation system) services (Alam et al. 2016), including urban parking availability (Kaplan et al. 2006) and mode \& time trip advice (Capato et al. 2016) offered to the commuter, and green (light) priority (Mitsakis et al. 2014) applied for public transportation vehicles. Urban parking availability provides parking information to its users to make informed decisions about available parking places. The service (to be implemented as a smartphone application or on an on-board unit within the vehicle) offers optimal advice to the user about the nearest available parking space, in order to minimize the search for a suitable parking location. Coupled with the parking availability service is the mode \& trip time advice service, which aims to provide a traveler with an itinerary for a multimodal transport journey, taking into account real-time information about options of different modes. In addition to these services provided to the driver, the green priority service aims to change the traffic signals' status in the path of a designated vehicle - in this case public transportation vehicles - in order to help reduce their travel time. This service is offered by the traffic manager at points where vehicles request priority for an intersection, and the traffic light controller determines in what way it can and will respond to the request.

When traveling into town from the commuter belt, the solution directs commuters by car to the nearest suitable parking location just outside the inner city, taking into account dynamic parking, user, traffic and public transport data. Consequently, mode \& trip time advice is offered to make it easier for commuters to travel onwards to their desired travel destination. As an incentive, the application offers public transport tickets for free or with reduced

Fig. 7 SDBM/R for green and comfortable commuting

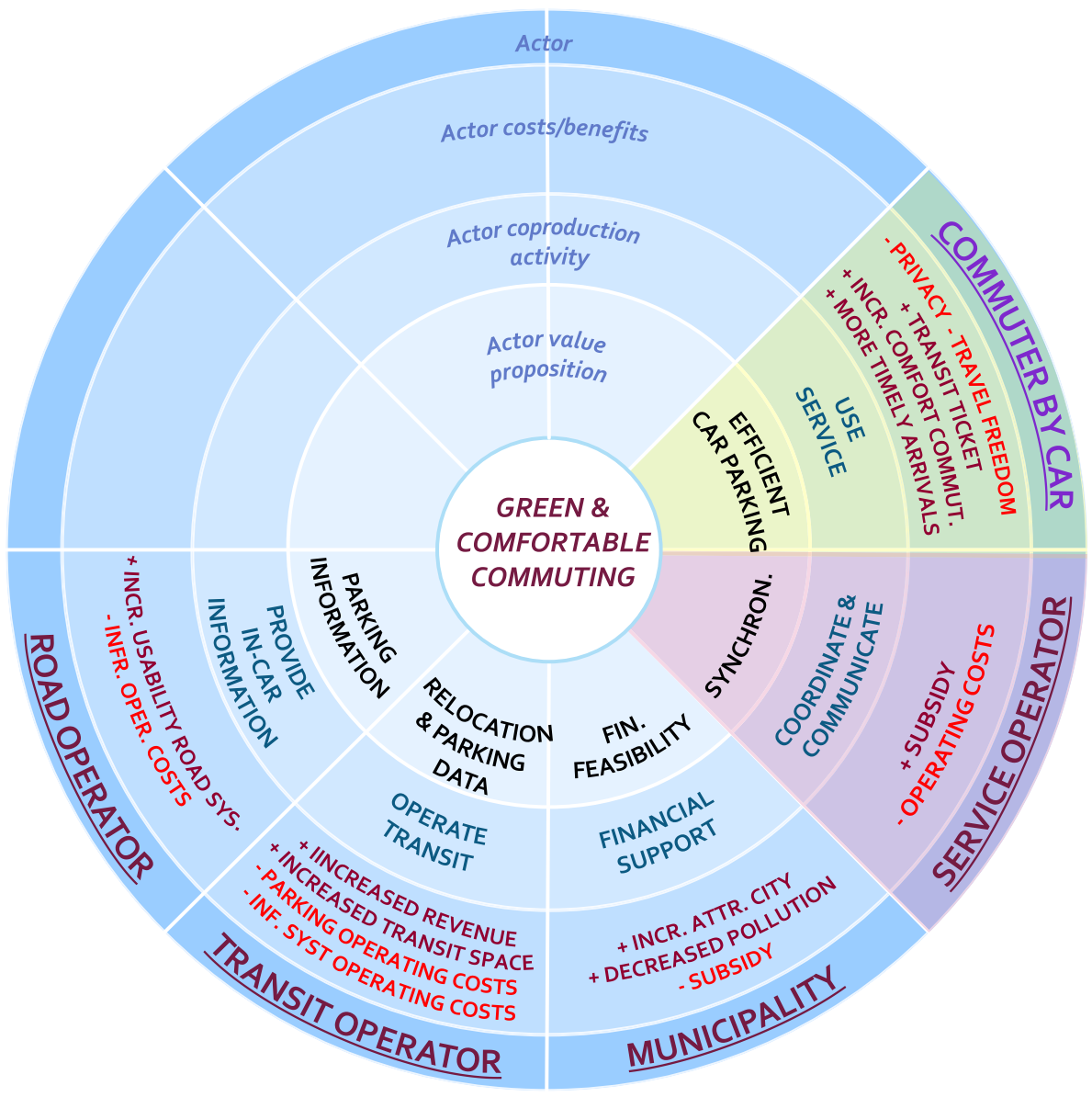


tariffs, depending on the current traffic conditions in the inner city. As unnecessary cruising for parking is reduced, commuters benefit from increased comfort. Moreover, traveling costs can be reduced as tickets are offered for free. The municipality in turn benefits from decreased pollution, less congestion and therefore an increased attractivity of the city itself.

The business model is complemented by the transit operator (i.e., public transportation provider), and the road operator (and traffic manager). The transit operator relocates commuters from the car parks to the vicinity of their final destination. The road operator complements the added value by using the green priority service for public transportation vehicles. It provides the parking information and benefits from a better usable road system at the cost of managing or operating the road infrastructure.

The participants of the workshop also designed different variants of the business model by including other enriching parties. For instance, as the commuters' timelines potentially improve, certain employers (companies) located in the inner city can also be included in the network to cover (a part of) the service fee. This can be attractive particularly for those companies that are expected to offer parking facilities to employees. Consequently, employers can benefit from green image and on-time personnel (and can potentially be subsidized for this behavior). Another variant includes a mobility as a service (MaaS) provider that offers relocation through other means (e.g., private taxis) as opposed to public transportation.

\section{Evaluating the Utility of SDBM/R through Surveys}

Although SDBM Radar has been developed as a joint effort of experts through focus groups and workshops, it should be applied and evaluated in real-life business settings (Hevner et al. 2004). As mentioned in Sect. 3, for the evaluation of SDBM/R we focused on its validity and utility. The workshops (which we described above in Sect. 5) aimed at evaluating the validity and provided the setting for industry professionals to experience the use of the radar for designing new business models and to observe the extent to which the SDBM/R is applicable and can be used for its intended purpose of use. For SDBM/R's utility, we conducted a survey among the participants who had used the SDBM/R, to elicit their views on its usefulness and its ease of use as a tool to design service-dominant business models.

\subsection{Survey Material}

After each workshop session, workshop participants were asked to fill out a survey questionnaire in a one-page paper format to gather their views on the utility of the SDBM/R. Out of 161 workshop attendants, 58 participated in the post-workshop surveys, leading to a participation rate of $36 \%$.

The survey questionnaire was assembled using a set of statements from the Technology Acceptance Model TAM (Davis 1989; Venkatesh and Davis 2000). TAM and its derivatives - e.g., (Venkatesh et al. 2003) - are the theories most commonly referred to in the literature and employed to predict and explain the acceptance of design artifacts, mainly through their perceived usefulness/utility and ease of use. It has been used as a theoretical basis for many empirical studies in the information systems field, including the acceptance of information systems methods and models (Moody 2003). The original TAM has three primary constructs: perceived ease of use, perceived usefulness, and intention to use (Davis 1989). Perceived usefulness refers to users' perception on the utility of the design artifact in providing gains to its user (Venkatesh et al. 2003). Perceived ease of use refers to "the degree to which a person believes that using a particular design artifact will be free from physical or mental effort". Finally, intention to use can be defined as the extent to which a person intends to use a particular design artifact. Intention to use is the most proximal antecedent to the artifact use and believed to be determined by perceived usefulness and ease of use.

All constructs of TAM are operationalized using multiple indicators which have been rigorously evaluated for reliability and validity (Davis 1989). Following the work in (Venkatesh and Davis 2000), we used 4 items for perceived usefulness and ease of use, and 2 for intention to use. In line with the approach followed in (Moody 2003), the wording of the items was modified to accommodate this research. The participants could express their level of agreement with each statement on a 5-point Likert scale, ranging from 1 (strongly disagree) to 5 (strongly agree).

In addition to questions regarding demographics of the participants, our survey included open-ended questions in order to gather more information about participants' experience with and views on the use of the method. These questions asked participants to indicate their opinion on the strong and weak points of the approach, the difficulties that they experienced in the use of it, and the aspects that could be improved. The questionnaire is given in Appendix A (available online via springerlink.com).

\subsection{Results and Discussion}

Using the SDBM/R, the practitioners that participated in the workshops were able to design a considerable number of service-dominant business model blueprints in the smart mobility domain (as listed in Table 1), many of which aim 
to address specific urban mobility challenges of their regions or cities. These business models and the feedback that we gathered from the participants during the workshops and through the open questions in the questionnaire are valuable to assess the validity of our approach. Respondents agreed that following an explicit method that structures the interactive design of service-dominant business models fostered the creation of innovative ideas. Participants indicated SDBM/R as an effective means for a diverse set of stakeholders to collaboratively design new business models. The emphasis on designing a business ecosystem with multiple stakeholders (as opposed to an organization centric approach) was considered a key point. Taking the customer and value-in-use as a starting point, being able to reflect the networked nature of business, explicit focus on both monetary and nonmonetary cost/ benefit items for all parties, and the way this information is visualized were considered as strong points of the approach. The respondents further agreed that the use of the approach created awareness on the value of agile, SD business thinking and provided inspiration for collaboration with different stakeholders. Below are two (literally translated) quotes from the participants of the workshops:

The approach appealed to me and I think it offers leads to further shape our projects and improve our stakeholder analysis.
An inspiring session. After our investigation of traffic flows, one should sit together (again) with business and government organizations to conceive a business model for a service.

The participants also mentioned a number of difficulties in the use of the approach and points for improvement. Some of these points were related also to the specific business model that they designed. Examples include the difficulty in deciding on the customer, in identifying core and enriching partners, as well as in identifying the core value-in-use for the business model without sufficiently embracing the SD mindset and possessing experience with its principles and terminology. Difficulties also emerged with regard to the different nature of cost/benefit items for each partner (e.g., monetary and nonmonetary) and how this challenges the viability/feasibility evaluation of the business model. Early evaluations were considered the key for taking strategic decisions about whether engaging in the business is worthwhile. The role of the moderator and his/ her level of experience not only in conducting and moderating such events but also in applying and communicating SD logic were also indicated as key factors for the successful use of the approach.

Figure 8 presents the responses for each item in the TAM-based questions of the survey. The results suggest a positive view on all measured constructs, i.e., the perceived usefulness, perceived ease of use and intention to use. All workshop participants considered the SDBM/R to be useful

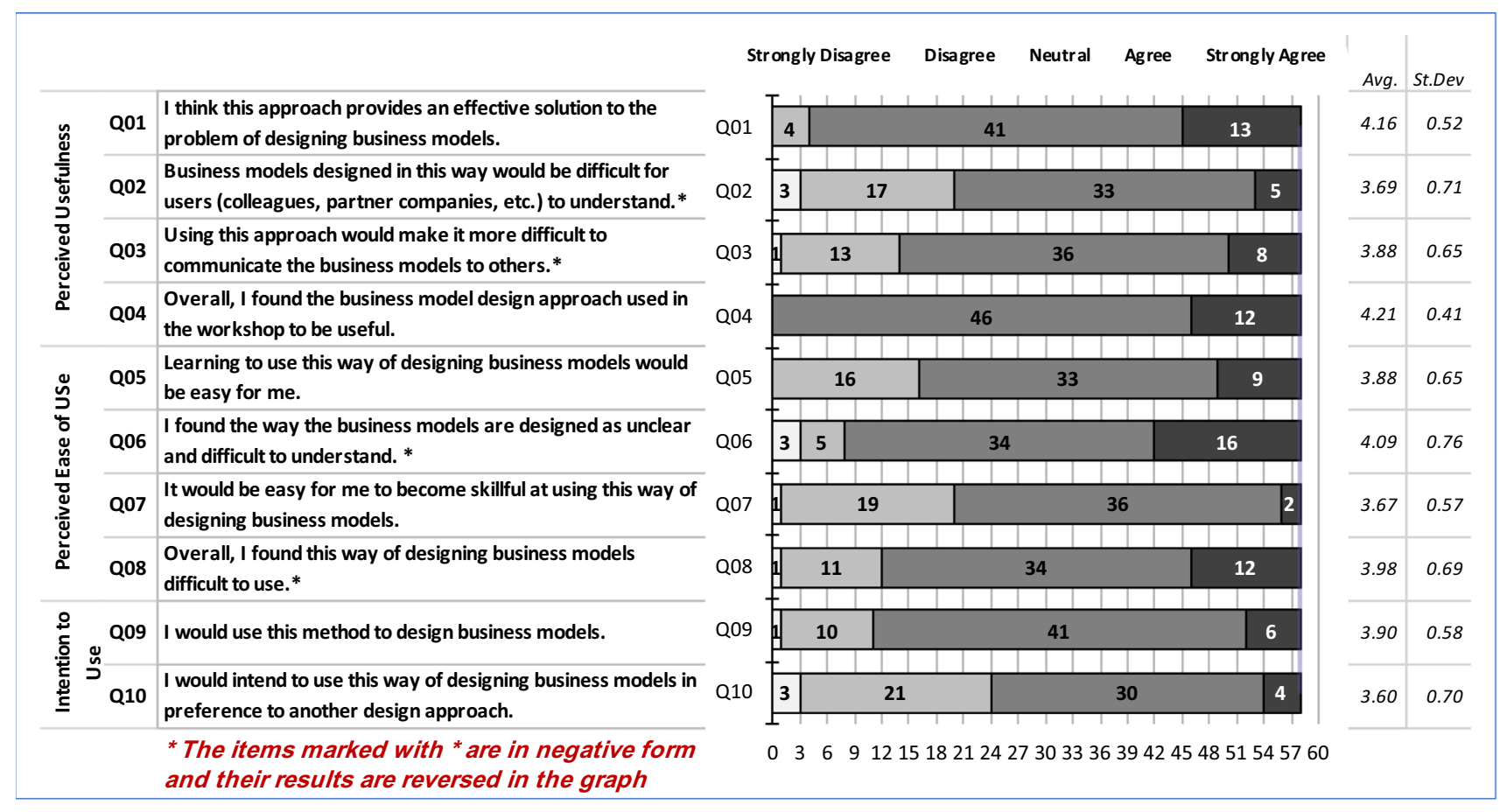

Fig. 8 Results of the survey on the perceived usefulness and ease of use of SDBM/R 
(Q4). The majority of them believed that it would be easy for them to learn and become skilful at using the radar and its design method (Q5, and Q7). Only a single participant indicated an overall negative view on the ease of use of the radar and the method $(\mathrm{Q} 8)$ and regarding the intention to use it (Q9). Overall, the responses of the participants for the model indicate a generally positive attitude towards using the radar.

\section{Conclusions}

The ongoing shift from goods-dominant logic to servicedominant logic has transformed the landscape of business innovation (Lusch and Nambisan 2015) - in many domains like smart mobility. We have experienced breakthrough innovations of intangible nature, which have focused on the development of new processes co-created with all actors (Prahalad and Ramaswamy 2004). These shifts have also expanded the role of information technology as a key facilitator in making innovations technically feasible and economically viable (Veit et al. 2014; Peters et al. 2016). However, in many business domains, the firms' agility in providing support for such innovations is heavily constrained by the business structures and IT platforms they use to deliver their services. This suggests the need for the development of new frameworks to structure servicedominant business modeling that can aid in integrating business strategy and business models on the one hand, and business services, processes, and IT platforms on the other hand, thereby facilitating viability of large-scale business innovations based on contemporary digital technologies.

Our prior work proposed a business engineering framework to assist companies in establishing a basis for structural agility and in instituting a service-dominant business environment. In this paper, we describe an integral part of this framework - i.e., the service-dominant business model radar (SDBM/R) and its method of use, for collaboratively designing business models. We designed $\mathrm{SDBM} / \mathrm{R}$ as a key component in the generation of complex digital innovations in a multi-stakeholder business environment. Such complex digital innovations often leverage multiple product-based digital technologies together with various capabilities of multiple parties to offer value to a customer in a particular context.

We brought together a diverse set of stakeholders and supported them in collaboratively designing new business models which target at today's urban mobility challenges. Collaborative workshops have shown to be effective means to quickly arrive at agile, customer-centric business models. The feedback gathered from the workshop participants and the results of the survey confirm the utility of the model and its potential to be adopted in practice. Our application of SDBM/R in these workshops in the smart mobility domain showed that SDBM/R can be effective in the generation of ideas for digital innovations that have actual impact.

\subsection{Contributions to Research and Practice}

This work contributes to the research on business models by integrating the concepts related to the core elements and design of business models with the principles of SD business. It provides a concrete basis for researchers and practitioners who aim to apply business modeling concepts to engineer SD business and generate digital innovations enabled by multiple stakeholders. Combined with our prior work on the SD strategy (Luftenegger et al. 2015), this work offers the foundation for structuring the business goals, and initial steps to align them to the business operations and implementation of SD business through the application of advanced digital technology. Using business models as a conceptual tool of alignment is significant, since in most of the existing alignment research this issue is addressed only at the strategic level (Al-Debei and Avison 2010).

The SDBM/R is a practical visual template that can help executives in startups or SMEs to design and communicate their new solutions to the market. The executives in established companies will also find it useful for rethinking their business models and transitioning from a GD to SD business. The business model blueprints presented in this paper and reported in other sources (Traganos et al. 2015; Grefen et al. 2016; Turetken and Grefen 2016; Turetken et al. 2018) target specifically at mobility challenges of a number of European cities. However, these challenges represent a common set that can inspire and act as a point of departure for concrete business models in other urban areas facing similar challenges.

\subsection{Limitations and Future Work}

Several practitioners have applied SDBM/R and evaluated its usefulness for designing new business models in workshop settings. However, as a limitation of this work, the implementation of many of these models is still ongoing (at the time of writing this paper). However, there are several (independent) initiatives within the companies who participated in our workshops where the SDBM/R is used as the starting point when designing new market offerings. For instance, currently one of these companies an information logistics company in a large international port- has adopted the proposed business engineering approach (that also includes SDBM/R) to design a servicedominant future for its business. In addition, the SDBM/R has been adopted by six European Consortia working in the 
area of mobility (C-ITS, automated driving), smart manufacturing, and logistics \& transportation in order to design and implement new business models. The SDBM/R has also been introduced on a national scale in The Netherlands by the authorities as an approach to inspire the stakeholders in the mobility and traffic management domain to explore new collaborative business thinking.

We consider business model innovation as a leverage to process innovation. Consequently, our future work will have a major focus on operationalizing service-dominant business models through service compositions to support business processes. These compositions will combine a number of (business) services offered by the parties in the business network and can be executed in process-oriented information systems to realize the value proposition. This also requires advanced approaches for effective portfolio management of these (business) services. Our future work will also consider the development of structured approaches for evaluating the viability of service-dominant business models taking both monetary and nonmonetary items into consideration.

Acknowledgements This work is partially supported by the C-MobILE (Accelerating C-ITS Mobility Innovation and depLoyment in Europe) project funded by the European Union's Horizon 2020 Research and Innovation Programme under Grant Agreement No 723311. The authors especially thank the workshop participants including the C-MobILE consortium partners for their participation. The authors also thank Egon Luftenegger and Marco Comuzzi for their contributions to the development of the business engineering framework.

Open Access This article is distributed under the terms of the Creative Commons Attribution 4.0 International License (http://crea tivecommons.org/licenses/by/4.0/), which permits unrestricted use, distribution, and reproduction in any medium, provided you give appropriate credit to the original author(s) and the source, provide a link to the Creative Commons license, and indicate if changes were made.

\section{References}

Abrell T, Pihlajamaa M, Kanto L et al (2016) The role of users and customers in digital innovation: insights from B2B manufacturing firms. Inf Manag 53:324-335. https://doi.org/10.1016/J.IM. 2015.12.005

Alam M, Ferreira J, Fonseca J (2016) Introduction to intelligent transportation systems. In: Alam M, Ferreira J, Fonseca J (eds) Intelligent transportation systems. Studies in systems, decision and control. Springer, Heidelberg, pp 1-17

Al-Debei MM, Avison D (2010) Developing a unified framework of the business model concept. Eur J Inf Syst 19:359-376

Al-Debei MM, El-Haddadeh R, Avison D (2008) Defining the business model in the new world of digital business. In: AMCIS 2008 proceedings

Amit R, Zott C (2001) Value creation in e-business. Strateg Manag J 22:493-520. https://doi.org/10.1002/smj.187
Angelidou M, Komninos N, Leal X, et al. (2015) Intelligent transport systems: glocal communities of interest for technology commercialization and innovation. In: Thomopoulos N, Givoni M, Rietveld P (eds) ICT for transport: opportunities and threats, Edward Elgar Publishing, Cheltenham, UK; Northampton, MA, USA, p 226

Asselin-Miller N, Biedka M, Gibson G, et al. (2016) Study on the deployment of C-ITS in Europe: final report. Framework contract on impact assessment and evaluation studies in the field of transport MOVE/A3/119-2013-Lot No 5 "Horizontal". Riccardo Energy \& Environment

Barrett M, Davidson E, Prabhu J, Vargo SL (2015) Service innovation in the digital age: key contributions and future directions. MIS Q 39:135-154. https://doi.org/10.25300/MISQ/2015/39:1.03

Baskerville R, Pries-Heje J, Venable J (2009) Soft design science methodology. In: Proceedings of the 4 th international conference on design science research in information systems and technology - DESRIST'09. ACM Press, New York

Bitner MJ, Ostrom AL, Morgan FN (2008) Service blueprinting: a practical technique for service innovation. Calif Manag Rev 50:66-94. https://doi.org/10.2307/41166446

Böhmann T, Leimeister JM, Möslein K (2014) Service systems engineering. Bus Inf Syst Eng 6:73-79. https://doi.org/10.1007/ s12599-014-0314-8

Bouwman H, Faber E, Haaker T et al (2008) Conceptualizing the STOF model. In: Bouwman H, De Vos H, Haaker T (eds) Mobile service innovation and business models. Springer, Heidelberg, pp 31-70

Bruns K, Jacob F (2014) Value-in-use and mobile technologies. Bus Inf Syst Eng 6:349-359. https://doi.org/10.1007/s12599-014-0349-x

Camarinha-Matos LM, Afsarmanesh H (2005) Collaborative networks: a new scientific discipline. J Intell Manuf 16:439-452

Capato S, Sena M, Blokpoel R, et al. (2016) Report on services developed for MOBiNET-Delv. 7.15

Chesbrough HW (2003) Open innovation: the new imperative for creating and profiting from technology. Harvard Business School Press, Boston

Cohen B, Kietzmann J (2014) Ride on! Mobility business models for the sharing economy. Organ Environ 27:279-296. https://doi. org/10.1177/1086026614546199

Davis FD (1989) Perceived usefulness, perceived ease of use, and user acceptance of information technology. MIS Q 13:319

De Castro V, Marcos E, Wieringa R (2009) Towards a serviceoriented mda-based ap-proach to the alignment of business processes with it systems: from the business model to a web service composition model. Int J Coop Inf Syst 18:225-260. https://doi.org/10.1142/S0218843009002038

De Vos H, Haaker T (2008) The STOF Method. In: Bouwman H, De Vos H, Haaker T (eds) Mobile service innovation and business models. Springer, Heidelberg, pp 115-136

Di Valentin C, Burkhart T, Vanderhaeghen D, et al (2012) Towards a framework for transforming business models into business processes. In: AMCIS 2012 proceedings

EC: C-ITS Deployment Platform (2016) C-ITS platform: final report - January 2016

EU Parliment (2010) Directive 2010/40/EU of the european parliment and of the council of 7 july 2010 on the framework for the deployment of intelligent transport systems (ITS) in the field of road transport and for interfaces with other modes of transport

Gawer A, Cusumano MA (2008) How companies become platform leaders. MIT Sloan Manag Rev 49:28-35

Gordijn J, Akkermans H (2001) Designing and evaluating e-business models. IEEE Intell Syst 16:11-17

Grefen P, Turetken O (2018) Achieving business process agility through service engineering in extended business networks. BPTrends, April 2018 
Grefen P, Luftenegger E, Linden EVD, Weisleder C (2013) Business agility through cross-organizational service engineering - the business and service design approach developed in the coprofind project. Beta working papers, vol 414. Eindhoven University of Technology, Eindhoven

Grefen P, Turetken O, Traganos K, et al (2015) Creating agility in traffic management by collaborative service-dominant business engineering. In: IFIP International federation for information processing: PRO-VE 2015 proceedings, pp 100-109

Grefen P, Turetken O, Razavian M (2016) Awareness initiative for agile business models in the dutch mobility sector: an experience report. Beta working papers, vol 505. Eindhoven University of Technology, Eindhoven

Gregor S, Hevner AR (2013) Positioning and presenting design science research for maximum impact. MIS Q 37:337-356

Grönroos C, Gummerus J (2014) The service revolution and its marketing implications: service logic vs service-dominant logic. Manag Serv Qual An Int J 24:206-229. https://doi.org/10.1108/ MSQ-03-2014-0042

Gummesson E (1995) Relationship marketing: its role in the service economy. In: Glynn WJ, Barnes JG (eds) Understanding services management. Wiley, Hoboken, pp 244-268

Hedman J, Kalling T (2003) The business model concept: theoretical underpinnings and empirical illustrations. Eur J Inf Syst 12:49-59. https://doi.org/10.1057/palgrave.ejis.3000446

Heikkila J, Heikkila M, Tinnila M (2008) The role of business models in developing business networks. In: Becker A (ed) Electronic commerce: concepts, methodologies, tools, and applications. information science reference (IGI Global), pp 221-231

Hevner AR, March S, Park J, Ram S (2004) Design science in information systems research. MIS Q 28:75-105

Kaplan LM, Hayes HR, Devries JS, Lindsay MG (2006) Method of operating a navigation system to provide parking availability information (Patent: Here Global BV. NAVTEQ North America LLC, USA)

Karpen IO, Bove LL, Lukas BA (2012) Linking service-dominant logic and strategic business practice: a conceptual model of a service-dominant orientation. J Serv Res 15:21-38. https://doi. org/10.1177/1094670511425697

Kontio J, Lehtola L, Bragge J (2004) Using the focus group method in software engineering: obtaining practitioner and user experiences. In: Proceedings of the 2004 international symposium on empirical software engineering. IEEE Computer Society, pp 271-280

KPMG (2017) Global Automotive Executive Survey 2017. KPMG

Legner C, Eymann T, Hess T et al (2017) Digitalization: opportunity and challenge for the business and information systems engineering community. Bus Inf Syst Eng 59:301-308. https:// doi.org/10.1007/s12599-017-0484-2

Luftenegger E (2014) Service-dominant business design. Ph.D. Thesis, Eindhoven University of Technology, The Netherlands

Luftenegger E, Comuzzi M, Grefen P (2013) The service-dominant ecosystem: mapping a service dominant strategy to a productservice ecosystem. In: Camarinha-Matos LM, Scherer RJ (eds) IFIP advances in information and communication technology (PRO-VE). Springer, Heidelberg

Luftenegger E, Comuzzi M, Grefen P (2015) Designing a tool for service-dominant strategies using action design research. Serv Bus 1:29. https://doi.org/10.1007/s11628-015-0297-7

Lusch RF, Nambisan S (2015) Service innovation: a service-dominant logic perspective. Manag Inf Syst Q 39:155-175

Lusch RF, Vargo SL (2006) Service-dominant logic: reactions, reflections and refinements. Mark Theory 6:281-288

Lusch RF, Vargo SL (2008) The service-dominant mindset. In: Hefley B, Murphy W (eds) Service science, management and engineering education for the 21 st century. Springer, Boston, pp 89-96
Lusch RF, Vargo SL, O’Brien M (2007) Competing through service: insights from service-dominant logic. J Retail 83:5-18. https:// doi.org/10.1016/j.jretai.2006.10.002

Magretta J (2002) Why business models matter. Harv Bus Rev 80:86-92

Massa L, Tucci C, Afuah A (2016) A critical assessment of business model research. Acad Manag Ann 11:73-104. https://doi.org/10. 5465/annals.2014.0072

Mingay S, Mesaglio M (2016) How to achieve enterprise agility with a bimodal capability. Gartner, Stamford

Mitsakis E, Grau JMS, Aifandopoulou G, et al. (2014) Large scale deployment of cooperative mobility systems in Europe: COMPASS4D. In: 2014 International conference on connected vehicles and expo (ICCVE). IEEE, pp 469-476

Moody DL (2003) The method evaluation model: a theoretical model for validating information systems design methods. In: ECIS 2003 proceedings, paper 79

Osterwalder A, Pigneur Y (2002) An ebusiness model ontology for modeling ebusiness. In: BLED 2002 proceedings, Article 2

Osterwalder A, Pigneur I (2010) Business model generation: a handbook for visionaries, game changers and challengers. Willey, New Jersey

Ostrom AL, Bitner MJ, Brown SW et al (2010) Moving forward and making a difference: research priorities for the science of service. J Serv Res 13:4-36

Parker GG, Van Alstyne MW, Choudary SP (2016) Platform revolution: how networked markets are transforming the economy - and how to make them work for you. Norton \& Company, W. W

Peffers K, Tuunanen T, Gengler CE, et al (2006) The design science research process: a model for producing and presenting information systems research. In: Proceedings of design research in information systems and technology (DESRIST'06), pp 83-106

Peters C, Maglio P, Badinelli R, et al. (2016) Emerging digital frontiers for service innovation. Commun Assoc Inf Syst 39: Article 8

Prahalad CK, Ramaswamy V (2004) The future of competition: cocreating unique value with customers. Harvard Business Review Press, Watertown

Rai A, Povlou PA, Im G, Du S (2012) Interfirm IT capability profiles and communications for cocreating relational value: evidence from the logistics industry. MIS Q 36:233-262

Roelens B, Poels G (2015) The development and experimental evaluation of a focused business model representation. Bus Inf Syst Eng 57:61-71. https://doi.org/10.1007/s12599-014-0363-z

Sanz JL, Becker V, Cappi J, et al. (2007) Business services and business componentization: new gaps between business and IT. In: IEEE international conference on service-oriented computing and applications (SOCA'07). IEEE, pp 271-278

Schneider S, Spieth P (2013) Business model innovation: towards an integrated future research agenda. Int $\mathrm{J}$ Innov Manag 17:1340001. https://doi.org/10.1142/S136391961340001X

Shafer SM, Smith HJ, Linder JC et al (2005) The power of business models. Bus Horiz 48:199-207

Suratno B, Ozkan B, Turetken O, Grefen P (2018) A method for operationalizing service-dominant business models into conceptual process models. In: Shishkov B (ed) Business modeling and software design. BMSD 2018. Lecture notes in business information processing, vol 319. Springer, Heidelberg, pp $133-148$

Timmers P (1998) Business models for electronic markets. Electron Mark 8:3-8. https://doi.org/10.1080/10196789800000016

Traganos K, Grefen P, den Hollander A et al (2015) Business model prototyping for intelligent transport systems: a service-dominant approach, vol 469. Eindhoven University of Technology, Eindhoven 
Turber S, vom Brocke J, Gassmann O, Fleisch E (2014) Designing business models in the era of internet of things. In: International conference on design science research in information systems DESRIST 2014. Springer, Heidelberg, pp 17-31

Turber S, vom Brocke J, Gassmann O (2015) Designing business models in the age of pervasive digitization. In: Academy of management annual meeting proceedings, 11600. https://doi.org/ 10.5465/ambpp.2015.11600

Turetken O, Grefen P (2016) Service-dominant business modeling in transport logistics. Beta working papers, vol 496. Eindhoven University of Technology, Eindhoven

Turetken O, Grefen P (2017) Designing service-dominant business models. In: European conference on information systems (ECIS 2017)

Turetken O, Grefen P, Gilsing R, Adali E (2018) Initial business models, C-MobILE - Accelerating C-ITS mobility innovation and deployment in Europe. Deliverable 2:5

United Nations (2014) World urbanization prospects: the 2014 revision. United Nations, Department of Economic and Social Affairs, Population Department. (ST/ESA/SER.A/366)

Vargo SL (2009) Toward a transcending conceptualization of relationship: a service-dominant logic perspective. J Bus Ind Mark 24:373-379. https://doi.org/10.1108/08858620910966255

Vargo SL, Lusch RF (2004) Evolving to a New dominant logic for marketing. J Mark 68:1-17. https://doi.org/10.1509/jmkg.68.1.1. 24036

Vargo SL, Lusch RF (2008) Service-dominant logic: continuing the evolution. J Acad Mark Sci 36:1-10

Veit D, Clemons E, Benlian A et al (2014) Business models: an information systems research agenda. Bus Inf Syst Eng 6:45-53. https://doi.org/10.1007/s12599-013-0308-y

Venable J, Pries-Heje J, Baskerville R (2012) A comprehensive framework for evaluation in design science research. International conference on design science research in information systems - DESRIST 2012. Springer, Heidelberg, pp 423-438
Venable J, Pries-Heje J, Baskerville R (2016) FEDS: a framework for evaluation in design science research. Eur J Inf Syst 25:77-89. https://doi.org/10.1057/ejis.2014.36

Venkatesh V, Davis FD (2000) A theoretical extension of the technology acceptance model: four longitudinal field studies. Manag Sci 46:186-204

Venkatesh V, Morris MG, Davis GB, Davis FD (2003) User acceptance of information technology: toward a unified view. MIS Q 27:425-478

vom Brocke J (2016) Interview with Martin Petry on "digital innovation for the networked society". Bus Inf Syst Eng 58:239-241. https://doi.org/10.1007/s12599-016-0431-7

Welke RJ (2015) Thinking tri-laterally about business processes, services and business models: an innovation perspective. In: vom Brocke J, Schmiedel T (eds) BPM - driving innovation in a digital world. Springer, Heidelberg, pp 31-47

Wieland H, Polese F, Vargo SL et al (2012) Toward a service (eco)systems perspective on value creation. Int J Serv Sci Manag Eng Technol 3:12-25. https://doi.org/10.4018/jssmet. 2012070102

Wise R, Baumgartner P (1999) Go downstream: the new profit imperative in manufacturing. Harv Bus Rev 77:133-141

Zolnowski A, Böhmann T (2014) Formative evaluation of business model representations - the service business model canvas. In: ECIS 2014 proceedings

Zolnowski A, Weiss C, Böhmann T (2014) Representing service business models with the service business model canvas - the case of a mobile payment service in the retail industry. In: 47th Hawaii international conference on system sciences (HICSS). IEEE, pp 718-727

Zott C, Amit R, Massa L (2011) The business model: recent developments and future research. J Manag 37:1019-1042. https://doi.org/10.1177/0149206311406265 